$$
\begin{aligned}
& \text { CONF-9610111--1 } \\
& \text { ANL/CHM/CP- } 91853
\end{aligned}
$$

\title{
Potential Energy Surfaces for CH Bond Cleavage Reactions
}

\section{PFIVED \\ JAN 161997 \\ USTI}

Lawrence B. Harding

Chemistry Division

Argonne National Laboratory

Argonne, IIL 60439

Abstract

Ab initio, multi-reference, configuration interaction calculations are reported for the reactions,

$$
\begin{aligned}
& \mathrm{CH}_{4} \leftrightarrow \mathrm{CH}_{3}+\mathrm{H} \\
& \mathrm{CH}_{3} \mathrm{~F} \leftrightarrow \mathrm{CH}_{2} \mathrm{~F}+\mathrm{H} \\
& \mathrm{CH}_{2} \mathrm{~F}_{2} \leftrightarrow \mathrm{CHF}_{2}+\mathrm{H} \\
& \mathrm{CHF}_{3} \leftrightarrow \mathrm{CF}_{3}+\mathrm{H}
\end{aligned}
$$

Two equivalent, barrier-less paths are found for the $\mathrm{CH}_{3}+\mathrm{H}$ recombination, two inequivalent, barrier-less paths are found for the $\mathrm{CH}_{2} \mathrm{~F}+\mathrm{H}$ and $\mathrm{CHF}_{2}+\mathrm{H}$ recombinations (depending on which side of the radical the hydrogen atom approaches) and only one barrier-less path is found for the $\mathrm{CF}_{3}+\mathrm{H}$ recombination. The minimum energy path for $\mathrm{H}$ atom approaching $\mathrm{CF}_{3}$ from the concave side is predicted to have a barrier of $27 \mathrm{kcal} / \mathrm{mole}$. Both the minimum energy path energies and the transitional frequencies as a function of $\mathrm{R}_{\mathrm{CH}}$ for all four reactions are predicted to be quite similar. 


\section{Introduction}

Potential surfaces for molecules at energies close to a dissociation limit are of interest because it is these regions that are of most importance in determining the rates of dissociation and recombination reactions. One of the simplest classes of dissociation/recombination reactions are the $\mathrm{CH}$ bond cleavage reactions. We have previously reported characterizations of potential surfaces for several simple CH bond cleavage/recombination reactions, including ${ }^{1-3}$ :

$$
\begin{aligned}
& \mathrm{CH}_{2} \leftrightarrow \mathrm{CH}+\mathrm{H} \\
& \mathrm{CH}_{3} \leftrightarrow \mathrm{CH}_{2}+\mathrm{H} \\
& \mathrm{HCCH} \leftrightarrow \mathrm{HCC}+\mathrm{H}
\end{aligned}
$$

These studies have shown that the rates of these reactions are sensitive both to features of the potential surface in the vicinity of the minimum energy paths (MEP) and to features of the potential surface sampled by large amplitude motion away from the MEP. In this paper we report characterization of potential surfaces for the following reactions:

$$
\begin{aligned}
& \mathrm{CH}_{4} \leftrightarrow \mathrm{CH}_{3}+\mathrm{H} \\
& \mathrm{CH}_{3} \mathrm{~F} \leftrightarrow \mathrm{CH}_{2} \mathrm{~F}+\mathrm{H} \\
& \mathrm{CH}_{2} \mathrm{~F}_{2} \leftrightarrow \mathrm{CHF}_{2}+\mathrm{H} \\
& \mathrm{CHF}_{3} \leftrightarrow \mathrm{CF}_{3}+\mathrm{H}
\end{aligned}
$$

There have already been fairly extensive theoretical studies reported on the potential surface ${ }^{4-12}$ and the kinetics ${ }^{13-16}$ for reaction (4). To our knowledge there has been only one theoretical study 17 of reaction (7) and no theoretical studies have yet been reported for reactions (5) and (6). It is the goal of the work reported here to provide reasonably accurate potential surfaces for all four reactions at the same level of theory so that meaningful comparisons can be made between the members of this series.

One aspect of these reactions, that will be a focus of this study, has to do with the coupling between the inversion mode of the methyl radicals and the reaction coordinate. The barriers to inversion and equilibrium inversion angles for the series of methyl radicals, $\mathrm{CH}_{3}, \mathrm{CH}_{2} \mathrm{~F}, \mathrm{CHF}_{2}$ and $\mathrm{CF}_{3}$, are summarized in Table 1 . The barriers to inversion in this series range from 0 to $\sim 30$ $\mathrm{kcal} / \mathrm{mole}^{18}$ and the equilibrium geometries range from planar to nearly tetrahedral. Consider a 


\section{DISCLAIMER}

Portions of this document may be illegible in electronic image products. Images are produced from the best available original document. 
recombination reaction involving one of these radicals. For $\mathrm{CH}_{3}$, it is clear that at some point along the reaction coordinate there must be significant coupling between the reaction coordinate and the inversion mode of the radical (the inversion angle must change by $\sim 20^{\circ}$ and the inversion force constant becomes much stiffer). At the other extreme, for $\mathrm{CF}_{3}$, there is no reason to expect strong coupling between the reaction coordinate and the inversion mode because the geometry of the $\mathrm{CF}_{3}$ radical and the geometry of the $\mathrm{CF}_{3}$ fragment in the $\mathrm{CF}_{3} \mathrm{H}$ molecule are quite similar. This reasoning suggests then that the coupling between the reaction coordinate and the inversion mode will decrease in the order $\mathrm{CH}_{3}+\mathrm{H}>\mathrm{CH}_{2} \mathrm{~F}+\mathrm{H}>\mathrm{CHF}_{2}+\mathrm{H}>\mathrm{CF}_{3}+\mathrm{H}$. However, there is another aspect to this question having to do with which side of the radical the hydrogen atom approaches. For $\mathrm{CH}_{3}$, since the radical is planar the two sides are equivalent and we expect two equivalent reaction paths. The other radicals though are all nonplanar and thus the two sides of these radicals are not equivalent. Each of these radicals has a convex side (which we will refer to here as the front-side) and a concave side (which we will refer to as the back-side). The argument outlined above concerning coupling between the reaction coordinate and the inversion mode clearly applies only to attack from the front-side of the radical. If recombination occurs from the back-side of any of these radicals an inversion will have to take place at some point along the reaction path. Thus an additional question to be addressed in this study is whether or not recombination can occur from the back-side of the three fluoro-methyl radicals.

All four of the above reactions have been studied experimentally in the recombination direction. The largest amount of work ${ }^{19-25}$ has been done on reaction (4). Two low pressure measurements ${ }^{26-27}$ of the rate of reaction (-7) have been reported. To our knowledge no measurements on reaction (5) and (6) have been published but at least one set of low pressure measurements ${ }^{28}$ have been made.

The paper is organized as follows. The details of the ab initio methods used are described in the next section. The characteristics of the MEP's resulting from these calculations are presented in Section III. In Section IV and V two types of large amplitude motion off the MEP's are considered; Section IV deals with motion of the departing hydrogen atom perpendicular to the reaction coordinate while Section V is concerned with coupling between the inversion mode of the radical and the reaction coordinate. 


\section{Ab Initio Methods}

The basis set used in most calculations was the correlation-consistent, polarized valence double zeta basis set of Dunning 29-31. For $\mathrm{CH}_{3}-\mathrm{H}$ some additional calculations were done with the augcc-pvdz and cc-pvtz basis sets. The former has added diffuse functions, the latter has higher angular momentum functions. With these basis sets, multi-configuration, self-consistent field calculations were carried out in which all four bond pairs were correlated. In this wavefunction, two orbitals were used to describe each bond pair (a bonding orbital and a correlating orbital). A restricted variant of an eight-orbital eight-electron complete active space calculation was then done in which excitations between bond pairs were excluded. This results in a total of 150 configurations. These orbitals were then used to perform multireference configuration interaction (MR-CI) calculations. In the MR-CI calculations only those three configurations associated with the correlation of the breaking $\mathrm{CH}$ bond were retained as reference configurations. We denote these calculations $\mathrm{RCI}+1+2$. For the dissociation of $\mathrm{CH}_{4}$ these $\mathrm{RCI}+1+2$ calculations were compared to $\mathrm{CI}$ calculations employing a full eight-orbital, eight-electron CAS $(\mathrm{CAS}+1+2)$ and were found to be in very good agreement. All calculations were carried out using the COLUMBUS package of $\operatorname{codes}^{32}$.

For each of the four reactions, MEP's were characterized in which the cleaving $\mathrm{CH}$ bond distance was taken to be the assumed reaction coordinate. This was accomplished by evaluating the energy for a grid of points, in which one of the $\mathrm{CH}$ bond distances is kept fixed while all other geometrical parameters are allowed to vary. This grid of energies was then fit to a five dimensional polynomial expansion which was then used both to locate the minimum in this five dimensional subspace and to define a five dimensional force field at the predicted minimum. Frequencies were then calculated using the standard mass-weighted atomic cartesian formalism (An atomic cartesian force constant matrix is evaluated numerically from the five dimensional polynomial fit. This matrix is then massweighted and diagonalized to obtain the bend and stretch frequencies). It is important to note that in this procedure the energy dependence along the assumed reaction coordinate (the active $\mathrm{CH}$ bond) is neglected. An alternative procedure is to include the energy dependence along the reaction coordinate (using a full six dimensional polynomial expansion rather than a five dimensional expansion) and then project the reaction coordinate out of the resulting atomic cartesian force constant matrix before diagonalizing the matrix. In general these two procedures do not yield the same final frequencies. The later method has been found to often yield physically unreasonable frequencies ${ }^{33-35}$. 
In addition to the MEP calculations described above, large amplitude motions away from the MEP were also examined. Two types of large amplitude motion were considered. First, motion of the departing hydrogen atom perpendicular to the MEP, i.e. orbiting around the methyl radical fragment. In these calculations the geometry of the methyl radical fragment was fixed at the equilibrium geometry of the radical.

The second type of large amplitude motion considered is the inversion or umbrella mode of the methyl radicals. The coordinate system used in this set of calculations can be described as follows. For the two symmetrical radicals, $\mathrm{CH}_{3}$ and $\mathrm{CF}_{3}$, the calculations described above led to the conclusion that the MEP lies along the $\mathrm{C}_{3 \mathrm{v}}$ axis of the radical fragment. For geometries with $\mathrm{C}_{3 \mathrm{v}}$ symmetry the inversion coordinate, $\theta$, can be defined simply as the angle, shifted by minus $90^{\circ}$, between the $\mathrm{C}_{3 \mathrm{v}}$ axis and any one of the three bonds of the methyl radical (by symmetry all three must make the same angle with the $C_{3 v}$ axis). With this definition $\theta=0$ corresponds to a planar radical, $\theta>0$ corresponds to the radical being pyramidalized away from the approaching $H$ and $\theta<0$ has the radical pyramidalized towards the approaching $\mathrm{H}$. To extend this definition of the inversion coordinate to both non- $\mathrm{C}_{3 \mathrm{v}}$ geometries of $\mathrm{CH}_{3}-\mathrm{H}$ and $\mathrm{CF}_{3}-\mathrm{H}$ and to the non- $\mathrm{C}_{3 \mathrm{v}}$ molecules, $\mathrm{CH}_{2} \mathrm{~F}-\mathrm{H}$ and $\mathrm{CHF}_{2}-\mathrm{H}$, we first define a pseudo- $\mathrm{C}_{3 \mathrm{v}}$ axis such that the axis makes equal angles with each of the three methyl radical bonds. Then the definition of the inversion coordinate is as above only now the angle is defined relative to this pseudo- $C_{3 v}$ axis rather than a true $C_{3 v}$ axis.

\section{Minimum Energy Paths}

Dissociation potentials for $\mathrm{CH}_{4}$ have been previously reported by several workers ${ }^{4-6}$. In the present work, the dissociation path of $\mathrm{CH}_{4}$ has been determined with two basis sets, cc-pvdz and aug-pvdz. Plots of the energy along these paths are shown in Figure 1 along with a third set of calculations in which the energy along the aug-pvdz path was reevaluated with the cc-pvtz basis set. All three levels of theory are in good agreement, with the aug-pvdz basis set leading to slightly lower energies in the long range region than either of the other basis sets. Also shown in Figure 1 are two Morse fits to the cc-pvdz interaction energies of the form,

$$
\mathrm{V}\left(\mathrm{R}_{\mathrm{CH}}\right)=\mathrm{D}_{\mathrm{e}}\left\{1-\exp \left[-\beta\left(\mathrm{R}_{\mathrm{CH}}-\mathrm{R}_{\mathrm{e}}\right)\right]\right\}
$$

which differ only in the exponential parameter, $\beta$. In one case this parameter is chosen to match the 
equilibrium harmonic frequency and in the other case a non-linear, least-squares fit is performed to the calculated points for $R_{C H}>2.5 \AA$. The values of $\beta$ from these fits are $1.9 \AA^{-1}$ and $2.2 \AA^{-1}$ respectively. These two exponential parameters differ by $\sim 15 \%$, with the latter giving very good agreement with the calculated, long-range points. As has been noted before ${ }^{6}$, the equilibrium Morse potential gives a poor fit to the long-range interaction energy.

MEP interaction energies for all four reactions are shown in Figure 2 along with Morse fits to the long-range points. The parameters of the Morse fits are summarized in Table 2. Very little variation is found between the Morse parameters for these three reactions indicating that neither the presence of the fluorine substituents nor the changes in the hybridization of the carbon radical orbital have much effect on the long range MEP energies.

The frequencies along the MEP's for all four reactions are displayed in Figure 3. For $\mathrm{CH}_{3}-\mathrm{H}$, the calculations predict that the pathway coincides with the $\mathrm{C}_{3 \mathrm{v}}$ axis of the methyl radical, for $\mathrm{CH}$ distances $<5 \AA$, i.e. the hydrogen atom approaches perpendicular to the plane of the methyl radical. In this region the transitional bend frequency corresponds to a doubly degenerate e mode. For $\mathrm{CH}$ distances $>5 \AA$, not shown in Figure 2, the MEP moves off the $\mathrm{C}_{3 \mathrm{v}}$ axis, down into the plane of the methyl radical, first bisecting two of the methyl radical $\mathrm{CH}$ bonds and at larger distances becoming collinear with one of the methyl radical $\mathrm{CH}$ bonds. This breaks the degeneracy of the transitional bend mode into an in-pane and out-of-plane bend. The calculated transitional bend frequencies are found to be in excellent agreement with previous calculations by Hase et $\mathrm{al}^{6}$.

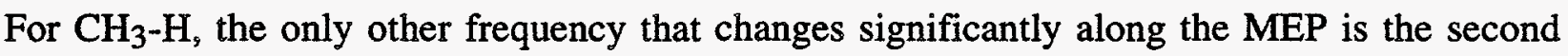
lowest frequency which corresponds to the inversion mode of the methyl radical. The frequency of the inversion mode starts increasing significantly as the $\mathrm{CH}$ distances less than $\sim 3.2 \AA$.

The MEP frequencies for the other three reactions, also shown in Figure 3, are qualitatively similar to those for $\mathrm{CH}_{3}-\mathrm{H}$. The two most significant differences are that the transitional bends of $\mathrm{CH}_{2} \mathrm{~F}-$ $\mathrm{H}$ and $\mathrm{CHF}_{2}-\mathrm{H}$ are non-degenerate due to the lack of a $\mathrm{C}_{3}$ symmetry axis and, for $\mathrm{CHF}_{2}-\mathrm{H}$ and $\mathrm{CF}_{3}-\mathrm{H}$, the inversion mode is not the lowest mode of the radical. For both the $\mathrm{CHF}_{2}$ radical and the $\mathrm{CF}_{3}$ radical, an FCF bend mode lies below the inversion mode. The coupling between this lowest frequency bend mode and the reaction coordinate is much smaller then that between the reaction coordinate and the inversion mode (the next higher frequency mode for both of these radicals) except that at $\sim 2 \AA$ we find a crossing between the transitional bends and the FCF bend for both $\mathrm{CHF}_{2}-\mathrm{H}$ and $\mathrm{CF}_{3}-\mathrm{H}$. 
Logarithmic plots of the transitional bend frequencies are displayed in Figure 4 along with leastsquares exponential fits of the form,

$$
\omega\left(R_{C H}\right)=\omega_{0} \exp \left(-\alpha R_{C H}\right)
$$

to the long-range variation of the frequencies. The values of $\omega_{0}$ and $\alpha$ derived from these fits are listed in Table 2. The variations in the rates of exponential decay between the four reactions, as characterized by the $\alpha^{\text {ss }}$, are not very large; the smallest and largest $\alpha$ 's are 1.4 and $1.7 \AA^{-1}$, respectively. While small, these variations are larger than the variations in the Morse exponential parameters.

\section{Hindered Rotations of the Methyl Fragments}

Previous studies have shown that rates of bond-dissocation/recombination reactions are sensitive not only to features of the potential surface in the vicinity of the MEP but also to features of the potential surface sampled by large amplitude motion away from the MEP. In this section and the next we report characterizations of the potential surfaces relevant to these large amplitude motions. In this section we focus on motions of the active hydrogen atom perpendicular to the reaction coordinate. This can be viewed either as an orbiting motion of the hydrogen around a stationary radical or a rotation of the radical relative to a stationary hydrogen atom.

In Figures 5-8 we show plots of the interaction energy for a hydrogen atom moving around fixed $\mathrm{CH}_{3}, \mathrm{CH}_{2} \mathrm{~F}, \mathrm{CHF}_{2}$, and $\mathrm{CF}_{3}$ radicals. Consider first the plot for $\mathrm{CH}_{3}+\mathrm{H}$, Figure 5. Since the $\mathrm{CH}_{3}$ radical is planar, we find two equivalent attractive pathways one for attack on each side of the methyl radical. The interaction energy becomes repulsive only when the hydrogen approaches within $\sim 30^{\circ}$ of the plane of the $\mathrm{CH}_{3}$ radical. In other words the angular width of each attractive path is $\sim 120^{\circ}$ or approximately two third's of the possible approach angles are attractive.

A plot comparing the energies for approach along the $\mathrm{C}_{3 \mathrm{v}}$ axis to those for approaches along the planar $\mathrm{C}_{2 \mathrm{v}}$ axes is shown in Figure 9. The difference between the $\mathrm{C}_{3 \mathrm{v}}$ energy and the lower of the two $\mathrm{C}_{2 \mathrm{v}}$ energies for a fixed value of $\mathrm{R}_{\mathrm{CH}}$ is the barrier for migrating from one MEP to the other at a fixed $\mathrm{CH}$ distance (we neglect here possible changes in the geometry of the methyl radical which are expected to be small in the dynamically most significant region). The most important point to 
note is that for $\mathrm{CH}$ distances less than $3.5 \AA$, the barriers to migration are higher than the asymptotic energy of $\mathrm{CH}_{3}+\mathrm{H}$. For $\mathrm{CH}$ distances greater than $3.5 \AA$ one or both of the $\mathrm{C}_{2} \mathrm{v}$ geometries lie slightly $(<0.1 \mathrm{kcal} / \mathrm{mole})$ below the $\mathrm{CH}_{3}+\mathrm{H}$ asymptote.

Figure 6 shows two plots of the $\mathrm{CH}_{2} \mathrm{~F}+\mathrm{H}$ interaction potential, one in a plane containing a $\mathrm{CH}$ bond and the other in a plane containing the $\mathrm{CF}$ bond. Since the $\mathrm{CH}_{2} \mathrm{~F}$ radical is not planar, the two sides of the radical are not equivalent. However, from the plots it is clear that barrier-less attacks are possible from either side of the radical. The pathway resulting from attack on the frontside of the radical is approximately twice as wide as the path resulting from attack on the back-side of the radical: One can also see from these plots that the orientation of the MEP is shifted significantly away from the fluorine atom.

Figure 7 shows two plots of the $\mathrm{CF}_{2} \mathrm{H}+\mathrm{H}$ interaction potential, one in a plane containing the $\mathrm{CH}$ bond and the other in a plane containing a CF bond. Again it is clear that barrier-less attacks are possible from either side of the radical, although now the pathway coming into the back-side of the radical is quite narrow and is in fact only visible in one of these two plots.

Finally, in Figure 8 a plot of the interaction potential for the $\mathrm{CF}_{3}+\mathrm{H}$ reaction is shown. The calculations indicate that both the front-side and back-side $\mathrm{C}_{3 \mathrm{v}}$ paths are minima with respect to angular motion of the hydrogen atom. However the back-side approach exhibits only a very shallow long-range attraction (due to dispersion type forces) before becoming repulsive. In other words, we find no evidence for a barrier-less path when the hydrogen approaches the back-side of the radical. Line plots of the energy as a function of $R_{C H}$ for the front-side and back-side $C_{3 v}$ approaches are shown in Figure 10. Also shown on this plot are the barriers (for fixed $\mathrm{R}_{\mathrm{CH}}$ ) to migrating the hydrogen between the two $\mathrm{C}_{3 \mathrm{v}}$ minima. These migration barriers are determined by a one dimensional search in which the geometry of the $\mathrm{CF}_{3}$ fragment is kept fixed, the $\mathrm{CH}$ distance is kept fixed and the $\mathrm{H}$ atom is constrained to lie in a symmetry plane of the $\mathrm{CF}_{3}$ radical. As for $\mathrm{CH}_{3}+\mathrm{H}$, we find these migration barriers to lie at most $0.1 \mathrm{kcal} /$ mole below the $\mathrm{CF}_{3}+\mathrm{H}$ asymptote.

\section{Methyl Inversion}

We now consider coupling between the reaction coordinate and the inversion mode. In Figure 11 we show plots of the energy as a function of the $\mathrm{CH}$ distance and the inversion angle, $\theta$, for the $\mathrm{CH}_{3}+\mathrm{H}$ and $\mathrm{CF}_{3}+\mathrm{H}$ reactions. For the $\mathrm{CH}_{3}+\mathrm{H}$ reaction, at large $\mathrm{CH}$ distances the optimum value 
of $\theta$ is zero (planar). As $R_{C H}$ decreases, the optimum $\theta$ gradually becomes increasingly positive (indicating that the $\mathrm{CH}_{3}$ hydrogens are bending away from the approaching hydrogen atom) reaching a value of $\sim 15^{\circ}$ at $\mathrm{R}_{\mathrm{CH}}=3$ au. For the $\mathrm{CF}_{3}+\mathrm{H}$ reaction, at large distances the inversion coordinate consists of a symmetrical double minimum. In one of these minima the fluorines are pyramidalized away from the hydrogen atom $\left(\theta=+17^{\circ}\right)$ while in the other minimum the fluorines are pyramidalized towards the hydrogen atom $\left(\theta=-17^{\circ}\right)$. These then correspond to the front-side and back-side paths, respectively. $\mathrm{As}_{\mathrm{CH}}$ decreases the front-side minimum in the inversion coordinate becomes deeper and the optimum $\theta$ increases slightly. At the same time the energy for the back-side minimum increases. At $\mathrm{R}_{\mathrm{CH}}=3.9$ au $\AA$ and $\theta=-4.1^{\circ}$ we find a transition state connecting these two paths. The energy at this transition state is $27.1 \mathrm{kcal} / \mathrm{mole}$ above the $\mathrm{CF}_{3}+\mathrm{H}$ asymptote, high enough to be unimportant under most conditions.

One can carry out similar analyses, for the $\mathrm{CH}_{2} \mathrm{~F}+\mathrm{H}$ and $\mathrm{CF}_{2} \mathrm{H}+\mathrm{H}$ reactions with one important difference, to locate the inversion barriers separating the front-side and back-side paths one must consider a minimum of three coordinates, $\mathrm{R}_{\mathrm{CH}}$, the inversion angle $\theta$, and the polar angle relative to the pseudo- $\mathrm{C}_{3}$ axis (this is because the MEP's for these two reactions lie in a symmetry plane rather than along a symmetry axis as for $\mathrm{CF}_{3}+\mathrm{H}$ ). These analyses predict that for both $\mathrm{CH}_{2} \mathrm{~F}+\mathrm{H}$ and $\mathrm{CF}_{2} \mathrm{H}+\mathrm{H}$ there are no true transition states connecting the front-side and back-side paths. For a fixed $\mathrm{R}_{\mathrm{CH}}$ one can locate a saddle point in the two angular coordinates which connects the two paths but none of these 2D saddle points are true transition states because they all have non-zero gradients in the $\mathrm{R}_{\mathrm{CH}}$ coordinate. For both $\mathrm{CH}_{2} \mathrm{~F}+\mathrm{H}$ and $\mathrm{CF}_{2} \mathrm{H}+\mathrm{H}$ the energies of these two dimensional inversion barriers drop more rapidly as a function of decreasing $R_{C H}$ than do the energies of the back-side MEP's. As a result, for sufficiently small values of $\mathrm{R}_{\mathrm{CH}}$, the back-side path disappears (merges with the front-side path). For the $\mathrm{CF}_{2} \mathrm{H}+\mathrm{H}$ reaction this happens at a $\mathrm{CH}$ distance of $2.2 \AA$ while for the $\mathrm{CH}_{2} \mathrm{~F}+\mathrm{H}$ reaction the paths merge at $\mathrm{R}_{\mathrm{CH}}=2.9 \AA$. Plots of the energy as a function of $\mathrm{R}_{\mathrm{CH}}$ for the front-side and back-side paths together with the inversion barrier separating them are shown in Figures 12 and 13 for the $\mathrm{CH}_{2} \mathrm{~F}+\mathrm{H}$ and $\mathrm{CF}_{2} \mathrm{H}+\mathrm{H}$ reactions, respectively. Also shown in these plots are the hindered rotor barriers separating the two paths analogous to those described above for $\mathrm{CH}_{3}+\mathrm{H}$ and $\mathrm{CF}_{3}+\mathrm{H}$. Another difference between the $\mathrm{CH}_{2} \mathrm{~F}+\mathrm{H}$ and $\mathrm{CF}_{2} \mathrm{H}+\mathrm{H}$ reactions and the $\mathrm{CH}_{3}+\mathrm{H}$ and $\mathrm{CF}_{3}+\mathrm{H}$ reactions is that the $\mathrm{CH}_{2} \mathrm{~F}+\mathrm{H}$ and $\mathrm{CF}_{2} \mathrm{H}+\mathrm{H}$ reactions have two different barriers connecting the front-side and back-side pathways via hindered rotation. For $\mathrm{CH}_{2} \mathrm{~F}+\mathrm{H}$, as the hydrogen atom rotates from one side to the other it can pass either the two $\mathrm{CH}$ bonds or between the $\mathrm{CF}$ bond and one of the $\mathrm{CH}$ bonds. At long $\mathrm{CH}$ distances the latter is lower in energy due to favorable dispersion forces, while at shorter distances 
the former is lower in energy. Similarly for $\mathrm{CF}_{2} \mathrm{H}+\mathrm{H}$, the migrating hydrogen atom can pass either between the two $\mathrm{CF}$ bonds or between the $\mathrm{CH}$ bond and one of the $\mathrm{CF}$ bonds.

\section{Conclusions}

The characteristics of the potential surfaces for reactions (4)-(7) show a number of strong similarities and a number of significant differences. The most important attributes of the MEP's, the dependence of both the energy and the transitional bend frequencies on the $\mathrm{CH}$ distance, for all four reactions are quite similar. The most significant differences have to do with the coupling between the inversion mode and the reaction coordinate. First, the distances at which this coupling becomes important varies quite markedly for these four reactions. The $\mathrm{CH}_{3}+\mathrm{H}$ reaction has the longest range coupling. At a $\mathrm{CH}$ distance of $3.2 \AA$, the $\mathrm{CH}_{3}+\mathrm{H}$ MEP inversion mode frequency is $50 \mathrm{~cm}^{-1}$ above its asymptotic value. The MEP inversion mode frequencies for the $\mathrm{CH}_{2} \mathrm{~F}+\mathrm{H}$ and $\mathrm{CHF}_{2}+\mathrm{H}$ reactions also increase with decreasing $\mathrm{CH}$ distances but more slowly than for $\mathrm{CH}_{3}+\mathrm{H}$. To obtain a $50 \mathrm{~cm}^{-1}$ increase in the MEP inversion mode for $\mathrm{CH}_{2} \mathrm{~F}+\mathrm{H}\left(\mathrm{CHF}_{2}+\mathrm{H}\right)$ one has to decrease the $\mathrm{CH}$ distance to $2.9 \AA(2.3 \AA)$. For the $\mathrm{CF}_{3}+\mathrm{H}$ reaction the MEP inversion frequency is almost independent of the $\mathrm{CH}$ distance except for a small $80 \mathrm{~cm}^{-1}$ dip around $2.4 \AA$.

One consequence of the coupling between the inversion mode and the reaction path is that for both $\mathrm{CH}_{2} \mathrm{~F}+\mathrm{H}$ and $\mathrm{CHF}_{2}+\mathrm{H}$ barrier-less recombination paths are found for attack from the back-side of the radical. In contrast, for $\mathrm{CF}_{3}+\mathrm{H}$ the calculations predict a $27 \mathrm{kcal} / \mathrm{mole}$ barrier to attack from the back-side of the radical.

\section{Acknowledgement}

This work was supported by the U.S. Department of Energy, Office of Basic Energy Sciences, Division of Chemical Sciences, under Contract W-31-109-ENG-38. 


\section{References:}

(1) L.B. Harding, R. Guadagnini, and G.C. Schatz, J. Phys. Chem. 97, 5472 (1993)

(2) A. F. Wagner and L. B. Harding, ACS Sympossium Series 502, 48, (1992)

(3) J.H. Kiefer, P.S. Mudipali, A.F. Wagner, and L.B. Harding, J. Chem. Phys. 105, 8075 (1996)

(4) P. Pulay, W. Meyer, and J.E. Boggs, J. Chem. Phys. 68, 5077 (1978)

(5) D.L. Gray and A.G. Robiette, Mol. Phys. 37, 1901 (1979)

(6) R.J. Duchovic, W.L. Hase, H.B. Schlegel, M.J. Frisch, and K. Ragavachari, Chem. Phys. Letters. 89, 120 (1982)

(7) R.J. Duchovic, W.L. Hase, and H.B. Schlegel, J. Phys. Chem. 88, 1339 (1984)

(8) S. Peyerimhoff, M. Lewerenz and M. Quack, Chem. Phys. Letters, 109, 563 (1984)

(9) M. Lewerenz and M. Quack, Chem. Phys. 88, 5408, (1988)

(10) F.B. Brown and D.G. Truhlar, Chem. Phys. Letts. 113, 441 (1985)

(11) D.M. Hirst, Chem. Phys. Letts. 122, 225 (1985)

(12) M. Sironi, D.L. Cooper, J. Gerratt, M. Raimondi, J. Amer. Chem. Soc. 112, 5054 (1990)

(13) M. Quack and J. Troe, Ber. Bunsenges. Physik. Chem. 81, 329 (1977)

(14) L.M. Raff, R. Viswanathan, and D.L. Thompson, J. Chem. Phys. 80, 6141 (1984) 
(15) W.L. Hase, S.L. Mondro, R.J. Duchovic, D.M. Hirst, J. Amer. Chem. Soc. 109, 2916 (1987)

(16) C.J. Cobos and J. Troe, Chem. Phys. Letters 113, 419 (1985)

(17) D.N. Shin, Y.S. Yoo, C.W. Park, J.W. Hahn, K. Song, Chem. Phys. Letters, 258, 613 (1996)

(18) M. Horn, M. Oswald, R. Oswald, and P. Botschwina, Ber. Bunsenges. Phys. Chem. 99, 323 (1995)

(19) R. Hartig, J. Troe and H.Gg. Wagner, 13th International Symposium on Combustion (Combustion Institute, Pittsburg, 1969) p. 147.

(20) M.J. Pilling and J.A. Robertson, Chem. Phys. Letters 33, 336 (1975)

(21) M.J. Pilling, J.A. Robertson and G.J. Rogers, Intern. J. Chem. Kinetics 8, 883 (1976)

(22) J.T. Cheng, Y.S. Lee, and C.T. Yeh, J. Phys. Chem. 81, 687 (1977)

(23) J.T. Cheng and C.T. Yeh, J. Phys. Chem. 81, 1982 (1977)

(24) R. Patrick, M.J. Pilling and G.J. Rogers, Chem. Phys. 53, 279 (1980)

(25) T.J. Sworski, C.J. Hochanadel, and P.J. Ogren, J. Phys. Chem. 84, 129 (1980)

(26) K.R. Ryan, I.C. Plumb, Plasma Chem. Plasma Proc. 4, 141 (1984)

(27) C.-P. Tsai and D. L. Mcfadden, J. Phys. Chem. 93, 2471 (1989)

(28) K. Hoyermann, private communication

(29) T.H. Dunning, Jr. , J. Chem. Phys. 90, 1007 (1989) 
(30) R.A. Kendall, T.H. Dunning, Jr., R.J. Harrison, J. Chem. Phys. 96, 6796(1992)

(31) D.E. Woon and T.H. Dunning, Jr., J. Chem. Phys. 98, 1358 (1993)

(32) Shepard, R.; I. Shavitt, R.M. Pitzer, D.C. Comeau, M. Pepper, H. Lischka, P.G. Szalay, R. Ahlrichs, F.B. Brown, and J.-G. Zhao, Int. J. Quantum Chem. S22, 149 (1988)

(33) G.A. Natanson, B.C. Garrett, T. Truong, T. Joseph, D.G. Truhlar, J. Chem. Phys. 94, 7875(1991)

(34) C.F. Jackels, Z. Gu, D.G. Truhlar, J. Chem. Phys. 102, 3188 (1995)

(35) J. Espinosa-Garcia and J.C. Corchado, J. Phys. Chem. 100, 16561 (1996) 


\section{Figure Captions:}

Figure 1. MEP energies for the $\mathrm{CH}_{3}+\mathrm{H}$ reaction. The circles are results using the cc-pvdz basis, squares using the aug-cc-pvdz basis and triangles using the cc-pvtz basis set. The solid line is a least squares fit of the long range cc-pvdz results to a Morse potential while the dashed line is an equilibrium Morse potential, as described in the text.

Figure 2. $\mathrm{MEP}$ energies for the $\mathrm{CH}_{3}+\mathrm{H}, \mathrm{CH}_{2} \mathrm{~F}+\mathrm{H}, \mathrm{CHF}_{2}+\mathrm{H}$ and $\mathrm{CF}_{3}+\mathrm{H}$ reactions. The solid circles are results using the cc-pvdz basis and the solid line is a least squares fit of the points with $\mathrm{R}_{\mathrm{CH}}>2.5 \AA$ to a Morse potential.

Figure 3. MEP frequencies for the $\mathrm{CH}_{3}+\mathrm{H}, \mathrm{CH}_{2} \mathrm{~F}+\mathrm{H}, \mathrm{CHF}_{2}+\mathrm{H}$ and $\mathrm{CF}_{3}+\mathrm{H}$ reactions. The mode correlating with the inversion mode of the radical is drawn with a dashed line.

Figure 4. Logarithmic plot of MEP transitional bend frequencies for the $\mathrm{CH}_{3}+\mathrm{H}, \mathrm{CH}_{2} \mathrm{~F}+\mathrm{H}$, $\mathrm{CHF}_{2}+\mathrm{H}$ and $\mathrm{CF}_{3}+\mathrm{H}$ reactions. The solid lines are the exponential fits as described in the text and Table 1.

Figure 5. Contour plot of the interaction energy for the $\mathrm{CH}_{3}+\mathrm{H}$ reaction. The $\mathrm{CH}_{3}$ fragment is fixed in its equilibrium geometry. Solid contours are positive, dash contours are negative, and the zero energy contour (defined to be the asymptotic energy of $\mathrm{CH}_{3}+\mathrm{H}$ ) is shown with a heavy solid line. The contour increment is $2.0 \mathrm{kcal} / \mathrm{mole}$.

Figure 6. Contour plots of the interaction energy for the $\mathrm{CH}_{2} \mathrm{~F}+\mathrm{H}$ reaction. The $\mathrm{CH}_{2} \mathrm{~F}$ fragment is fixed in its equilibrium geometry. The upper plot is in a plane containing a $\mathrm{CH}$ bond while the lower plot is in a plane containing the CF bond. Other plotting conventions are the same as in Figure 5.

Figure 7. Contour plots of the interaction energy for the $\mathrm{CHF}_{2}+\mathrm{H}$ reaction. The $\mathrm{CHF}_{2}$ fragment is fixed in its equilibrium geometry. The upper plot is in a plane containing the $\mathrm{CH}$ bond while the lower plot is in a plane containing a CF bond. Other plotting conventions are the same as in Figure 5. 
Figure 8. Contour plot of the interaction energy for the $\mathrm{CF}_{3}+\mathrm{H}$ reaction. The $\mathrm{CF}_{3}$ fragment is fixed in its equilibrium geometry. Plotting conventions are the same as in Figure 5.

Figure 9. $\mathrm{CH}_{3}+\mathrm{H}$ energies as a function of $\mathrm{R}_{\mathrm{CH}}$ for the $\mathrm{C}_{3 \mathrm{v}}$ and two $\mathrm{C}_{2 \mathrm{v}}$ approaches. The $\mathrm{CH}_{3}$ fragment is fixed in its equilibrium geometry.

Figure 10. $\mathrm{CF}_{3}+\mathrm{H}$ energies as a function of $\mathrm{R}_{\mathrm{CH}}$ for the two $\mathrm{C}_{3 \mathrm{v}}$ approaches and the barrier between them. The $\mathrm{CF}_{3}$ fragment is kept fixed in its equilibrium geometry.

Figure 11. Contour plots of the interaction energy as a function of $\mathrm{R}_{\mathrm{CH}}$ and the inversion coordinate, $\theta$, for the $\mathrm{CH}_{3}+\mathrm{H}$ and $\mathrm{CF}_{3}+\mathrm{H}$ reactions. The approaching hydrogen is constrained to lie on the $\mathrm{C}_{3 \mathrm{v}}$ axis. All other geometrical parameters are kept fixed. The contour increment is 5 $\mathrm{kcal} / \mathrm{mole}$. Other plotting conventions are the same as in Figure 5.

Figure 12. $\mathrm{CH}_{2} \mathrm{~F}+\mathrm{H}$ energies as a function of $\mathrm{R}_{\mathrm{CH}}$ for the front-side and back-side MEP's and the barriers between them. The $\mathrm{CH}_{2} \mathrm{~F}$ fragment is kept fixed in its equilibrium geometry.

Figure 13. $\mathrm{CHF}_{2}+\mathrm{H}$ energies as a function of $\mathrm{R}_{\mathrm{CH}}$ for the front-side and back-side MEP's and the barriers between them. The $\mathrm{CHF}_{2}$ fragment is kept fixed in its equilibrium geometry. 
Table 1. Calculated $\mathrm{RCI}+1+2 / \mathrm{cc}-\mathrm{pvdz}$ equilibrium geometries and barriers to inversion for $\mathrm{CH}_{3}$, $\mathrm{CH}_{2} \mathrm{~F}, \mathrm{CHF}_{2}$ and $\mathrm{CF}_{3}$.

$\begin{array}{llll}\mathrm{CH}_{3} & \mathrm{CH}_{2} \mathrm{~F} & \mathrm{CF}_{2} \mathrm{H} & \mathrm{CF}_{3}\end{array}$

$\mathbf{R}_{\mathrm{CH}}(\AA)$

$\mathrm{R}_{\mathrm{CF}}(\AA)$

1.09

1.09

1.09

1.34

1.32

1.31

$\mathrm{HCH} \angle$

$120.0^{\circ}$

$122.2^{\circ}$

$114.6^{\circ}$

FCF $\angle$

$\theta^{\mathrm{a}}$

$0.0^{\circ}$

$9.9^{\circ}$

$15.2^{\circ}$

$\mathrm{V}(\mathrm{kcal} / \mathrm{mole})$

0.0

0.7

8.5

$17.5^{\circ}$

32.6

aEquilibrium inversion angle as defined in text. 
Table 2. Parameters characterizing long-range Morse fits to the MEP energies and long range exponential fits to the MEP transitional frequencies for the four reactions, $\mathrm{CH}_{4} \leftrightarrow \mathrm{CH}_{3}+\mathrm{H}, \mathrm{CH}_{3} \mathrm{~F}$ $\leftrightarrow \mathrm{CH}_{2} \mathrm{~F}+\mathrm{H}, \mathrm{CH}_{2} \mathrm{~F}_{2} \leftrightarrow \mathrm{CHF}_{2}+\mathrm{H}$ and $\mathrm{CHF}_{3} \leftrightarrow \mathrm{CF}_{3}+\mathrm{H}$.

Reaction

$\beta\left(\AA^{-1}\right)$

$\omega_{0}\left(\mathrm{~cm}^{-1}\right)$

$\alpha\left(\AA^{-1}\right)$

$\mathrm{CH}_{4} \leftrightarrow \mathrm{CH}_{3}+\mathrm{H}$

2.2

22000

1.5

16000

1.4

$\mathrm{CH}_{3} \mathrm{~F} \leftrightarrow \mathrm{CH}_{2} \mathrm{~F}+\mathrm{H}$

2.2

14000

1.5

17000

1.5

$\mathrm{CH}_{2} \mathrm{~F}_{2} \leftrightarrow \mathrm{CHF}_{2}+\mathrm{H}$

2.2

15000

1.6

$\mathrm{CHF}_{3} \leftrightarrow \mathrm{CF}_{3}+\mathrm{H}$

2.3

20000

1.7 


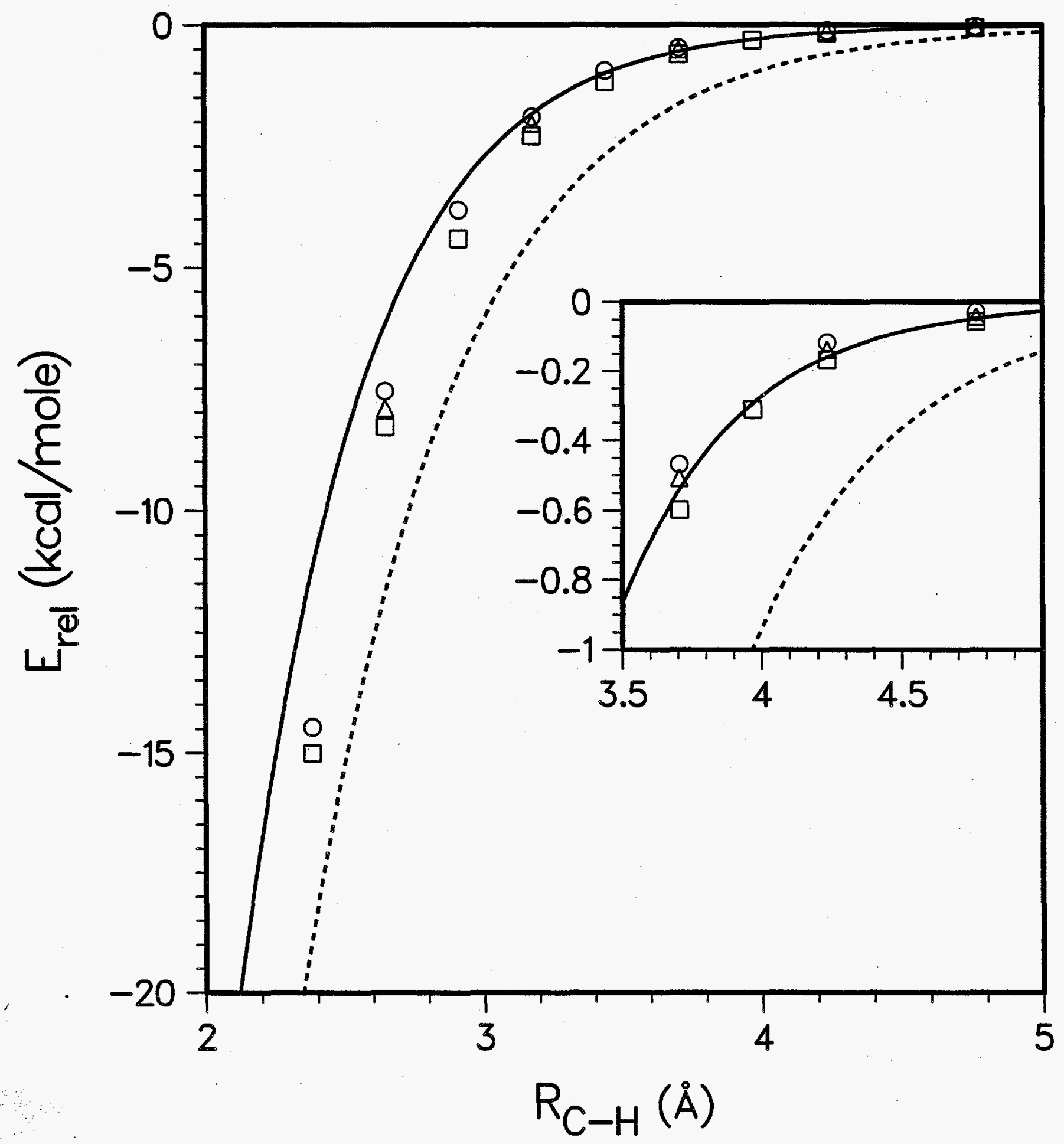

figl 

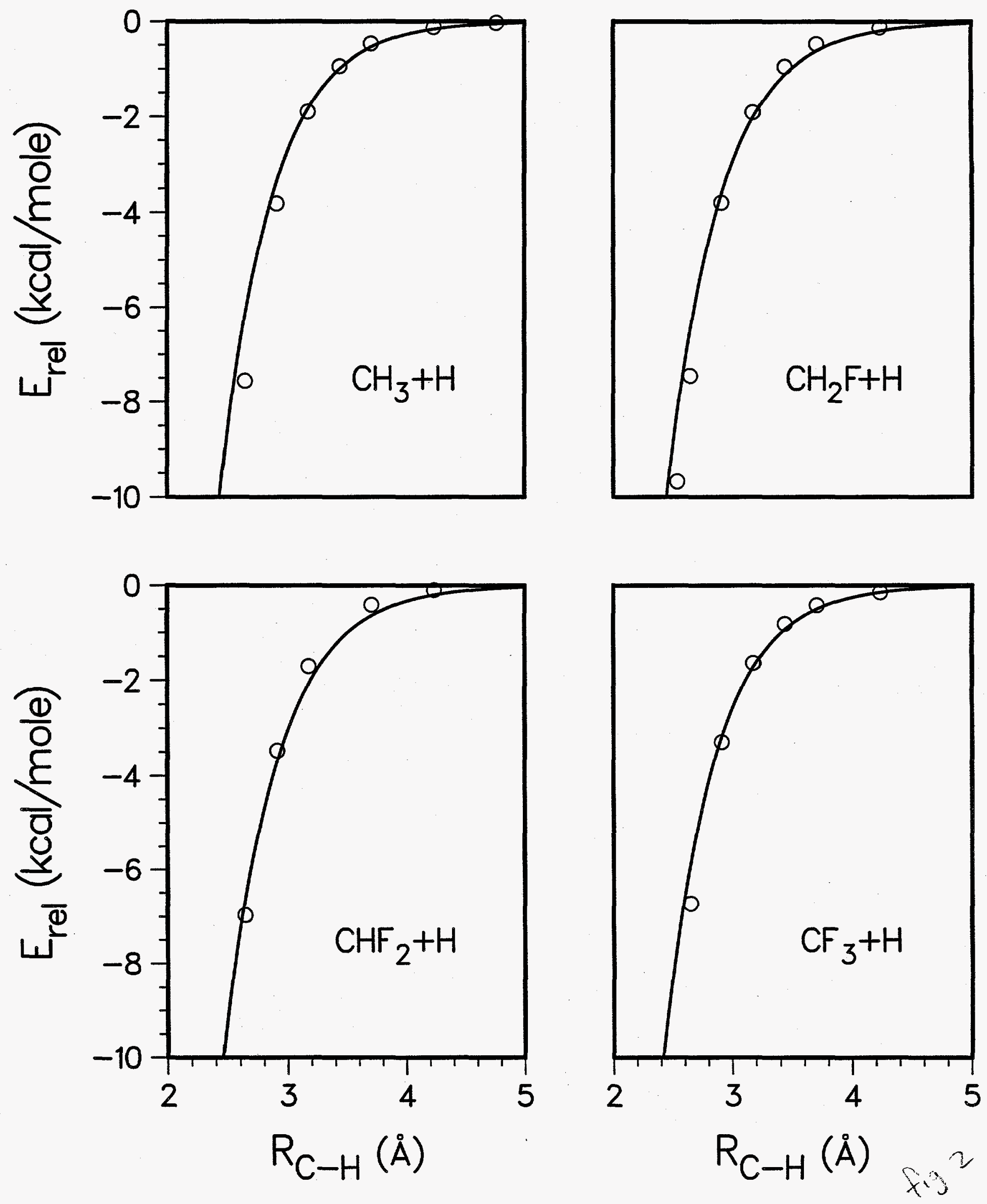

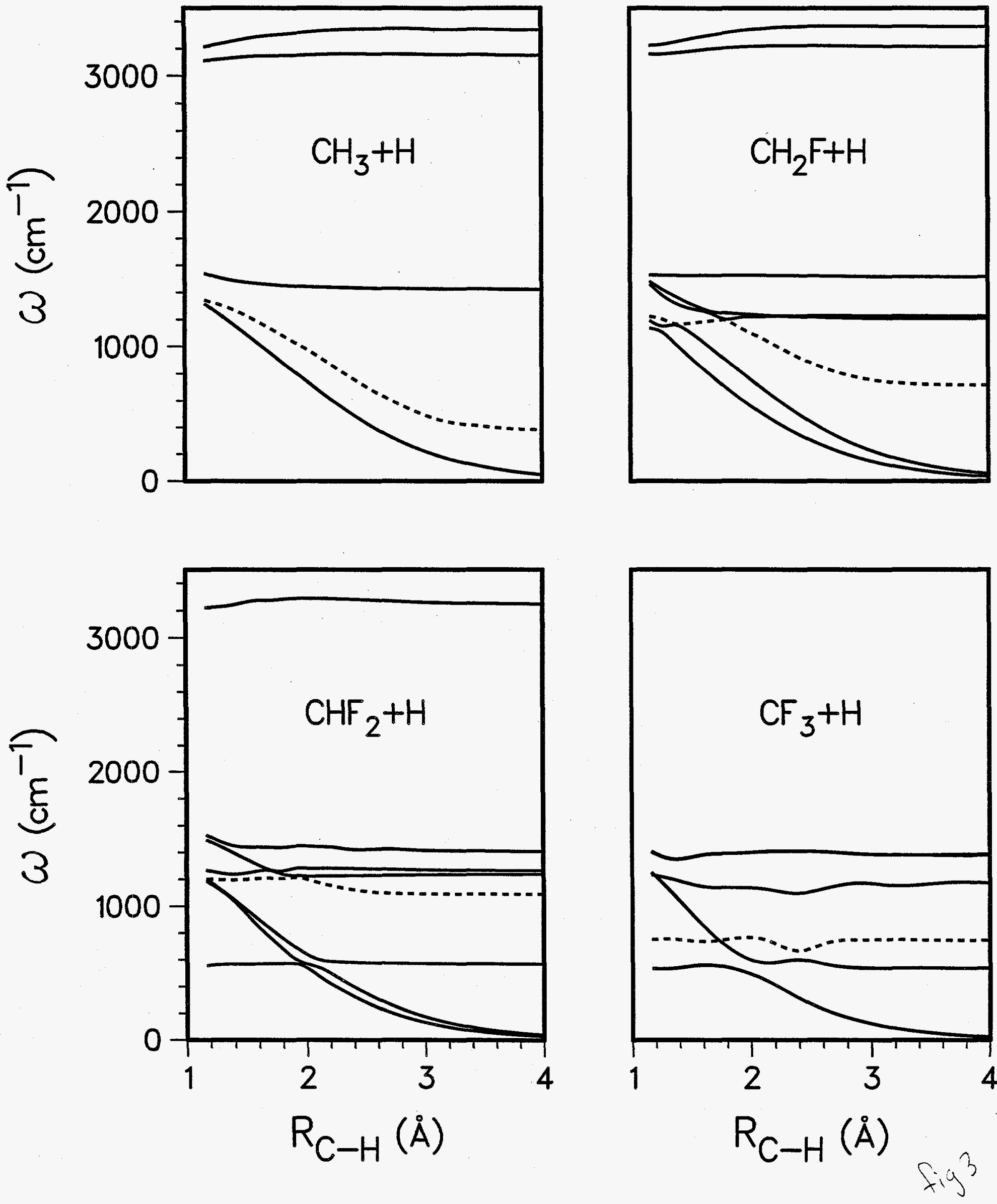

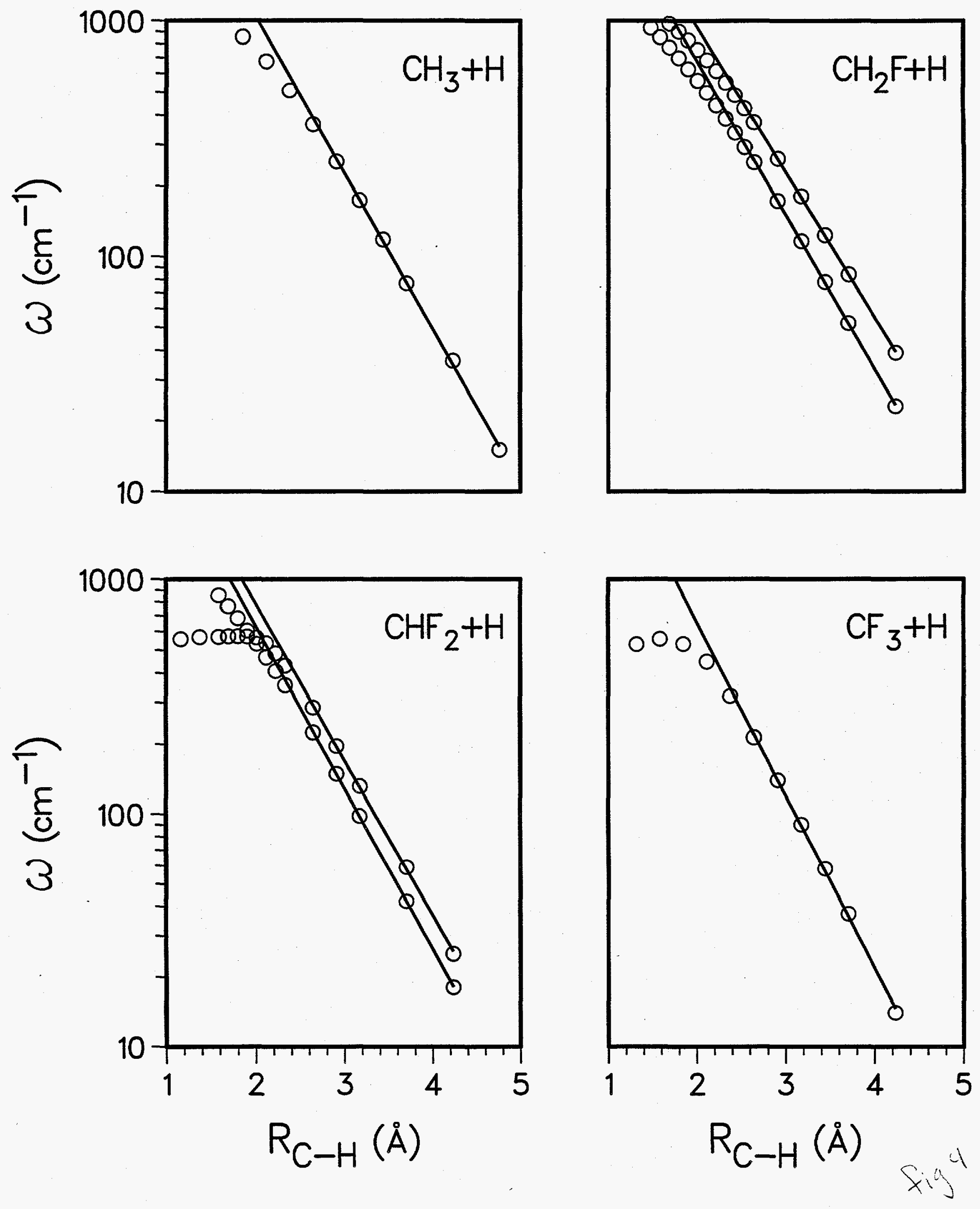


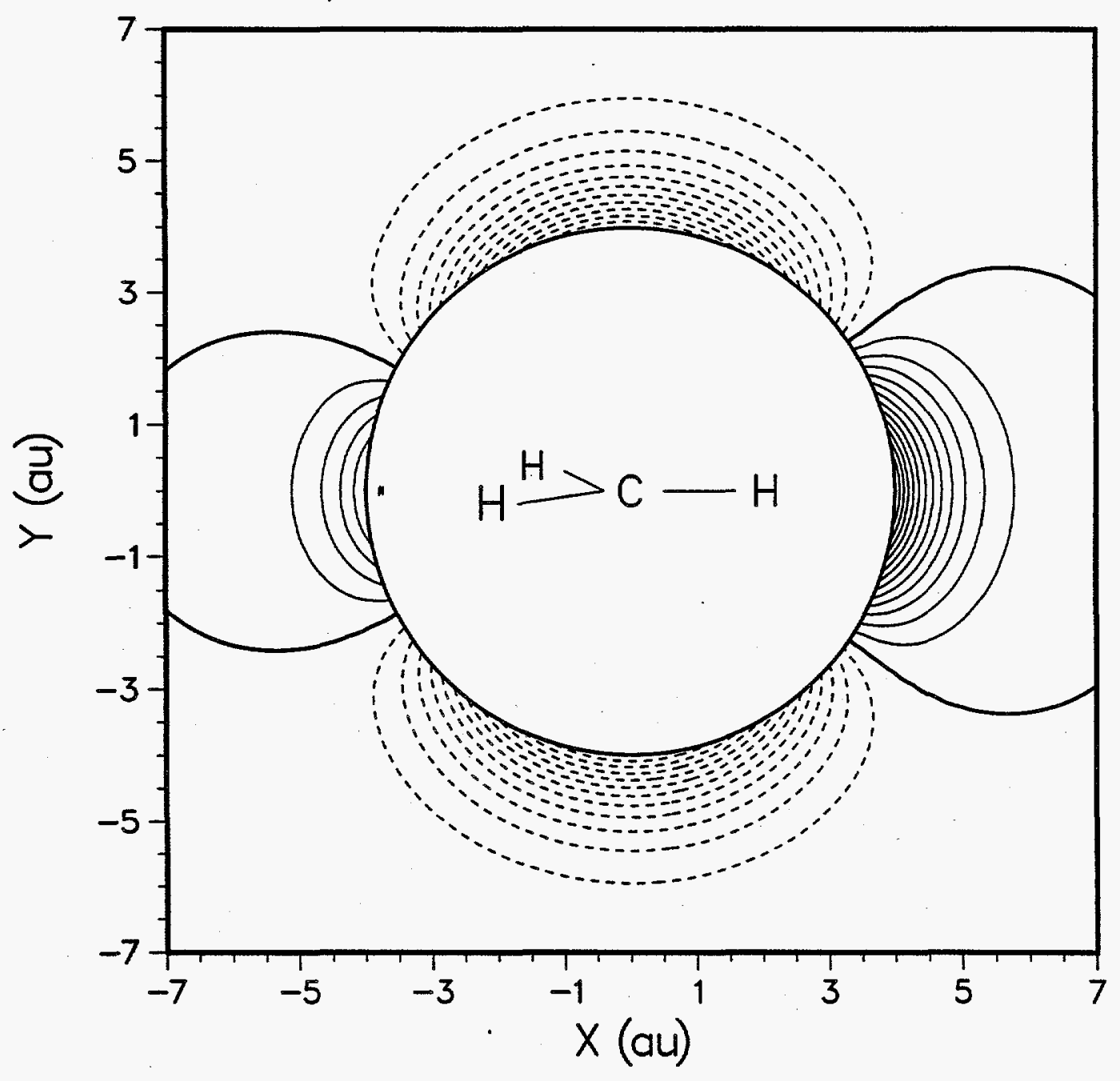



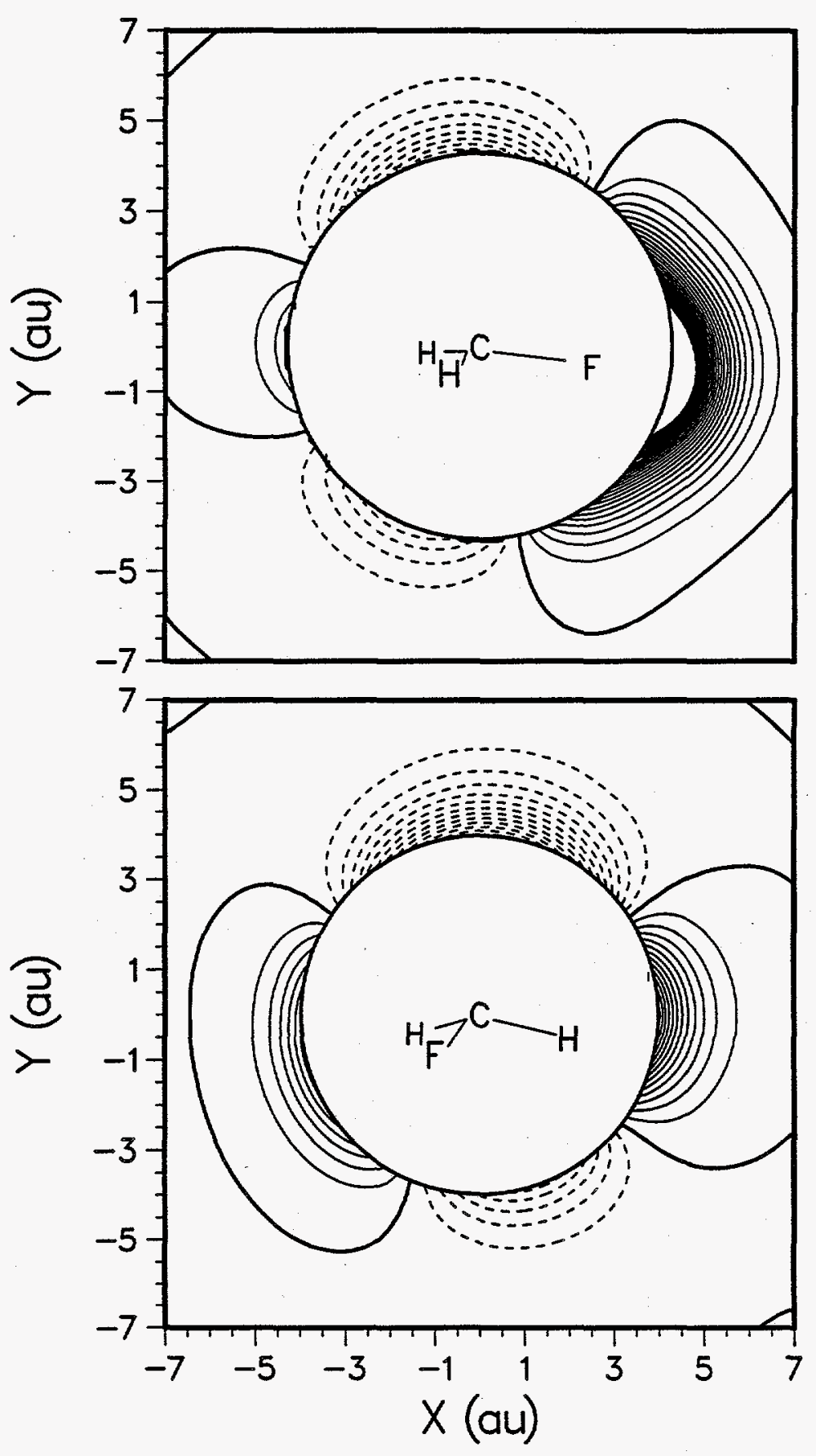

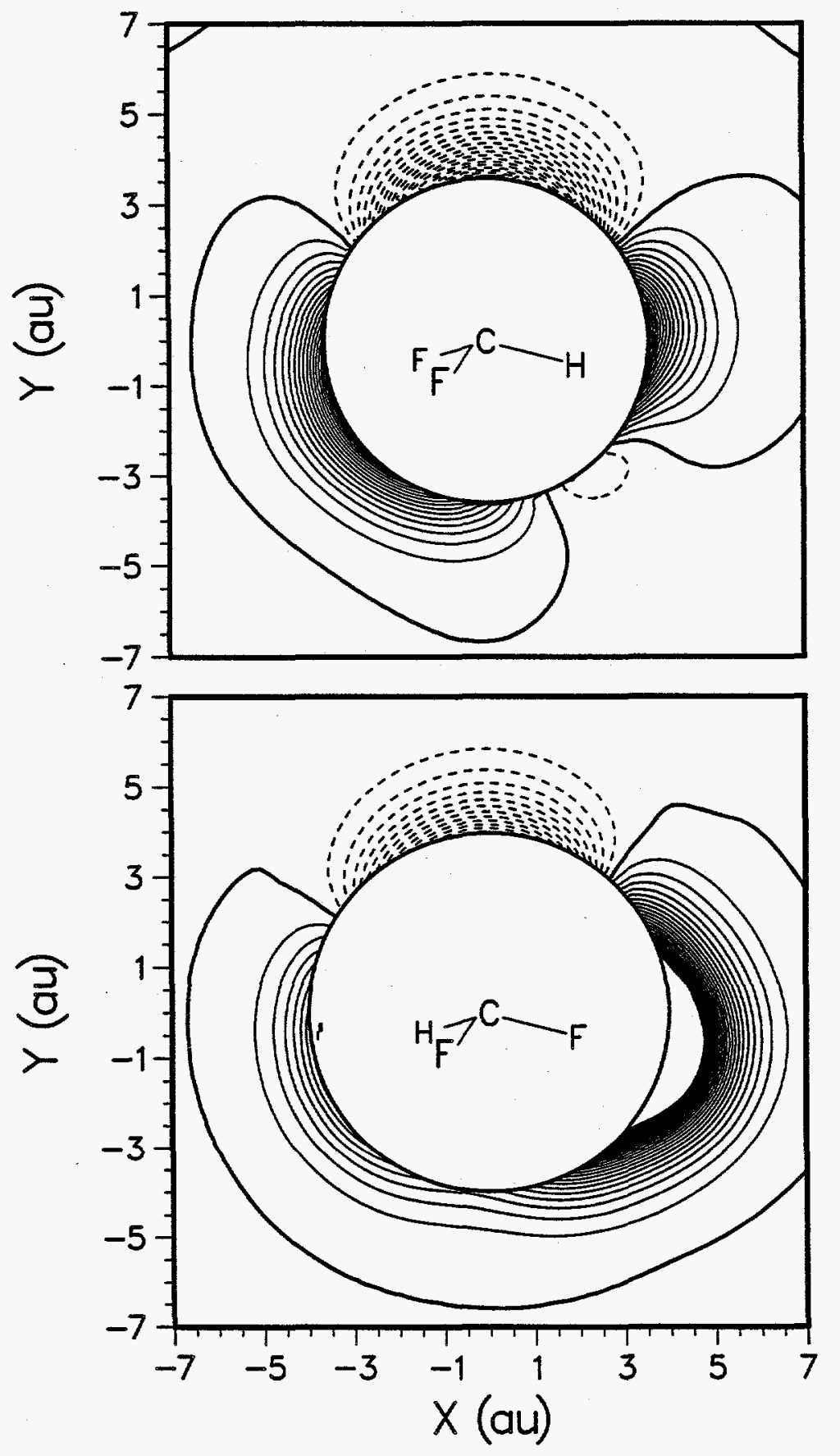

sign 


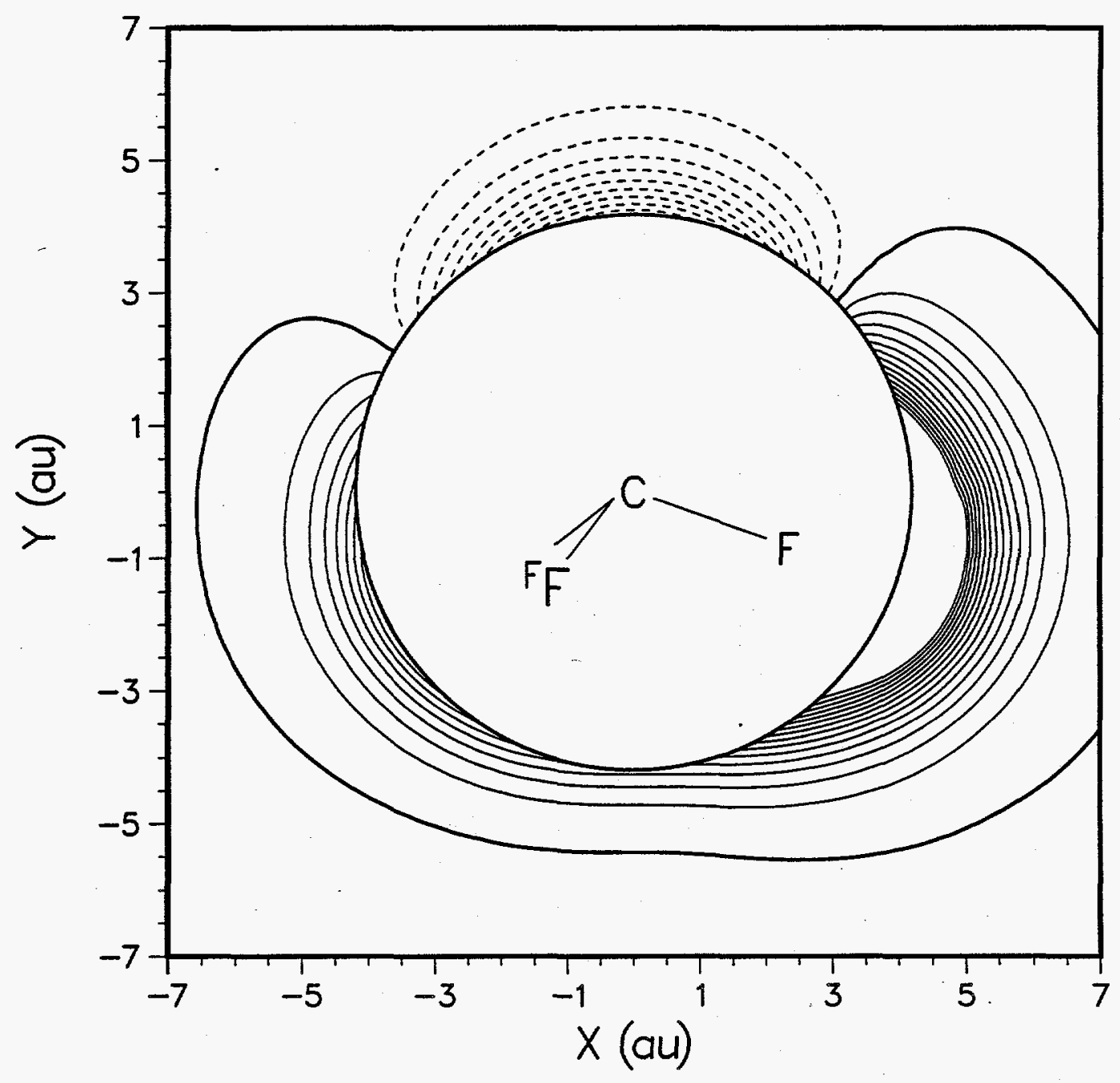

$$
8 i^{3} .
$$




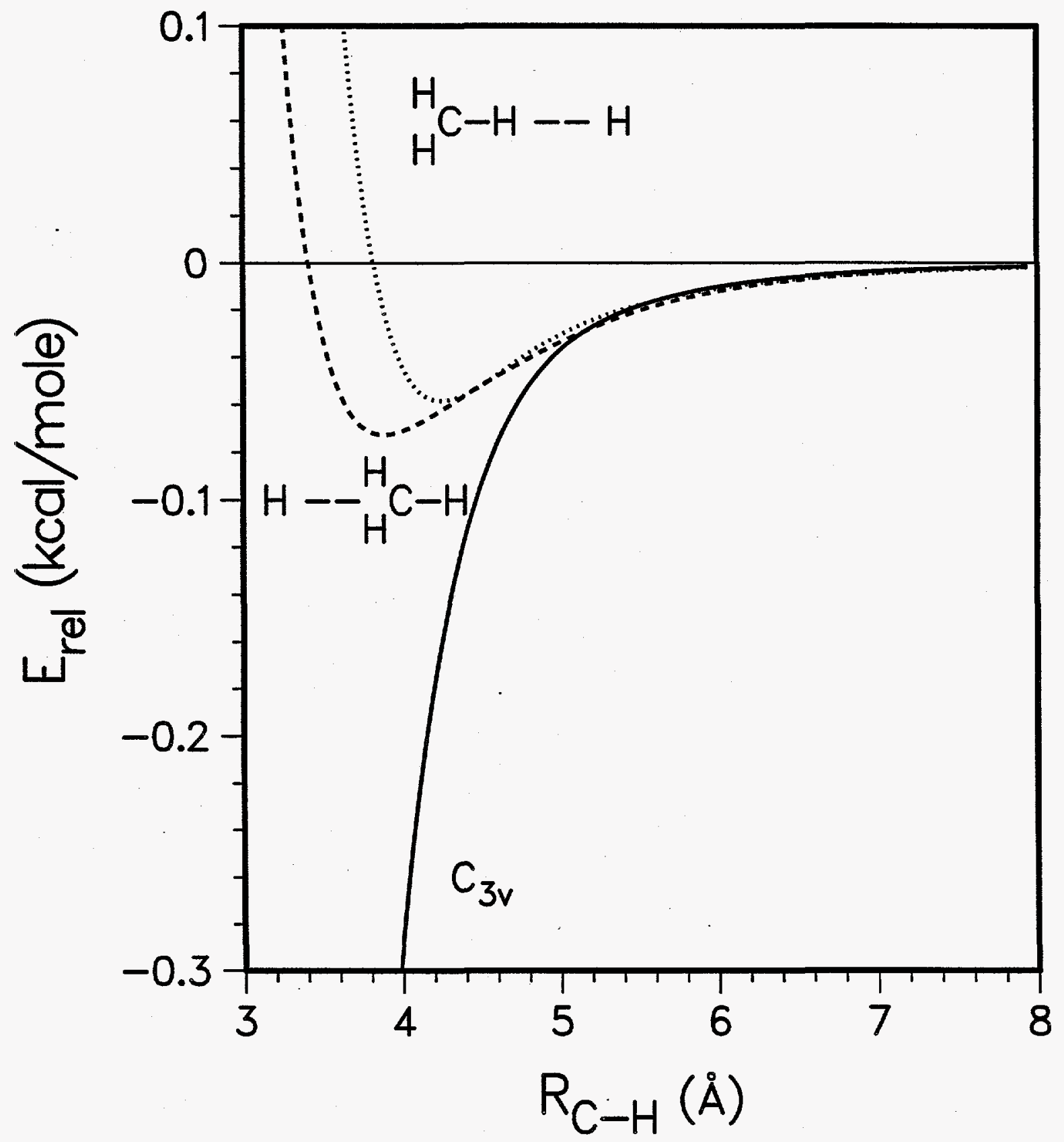




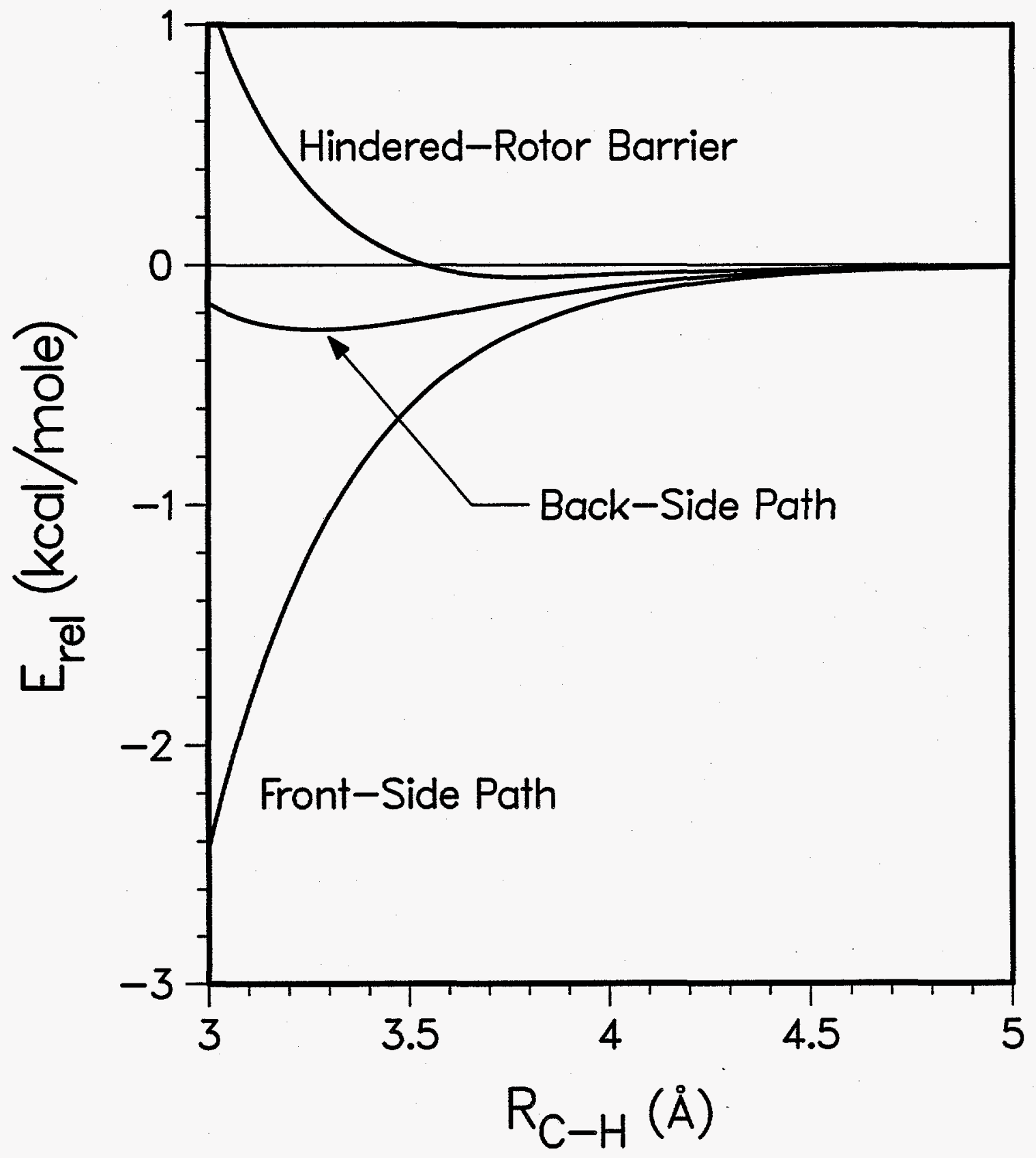

10 

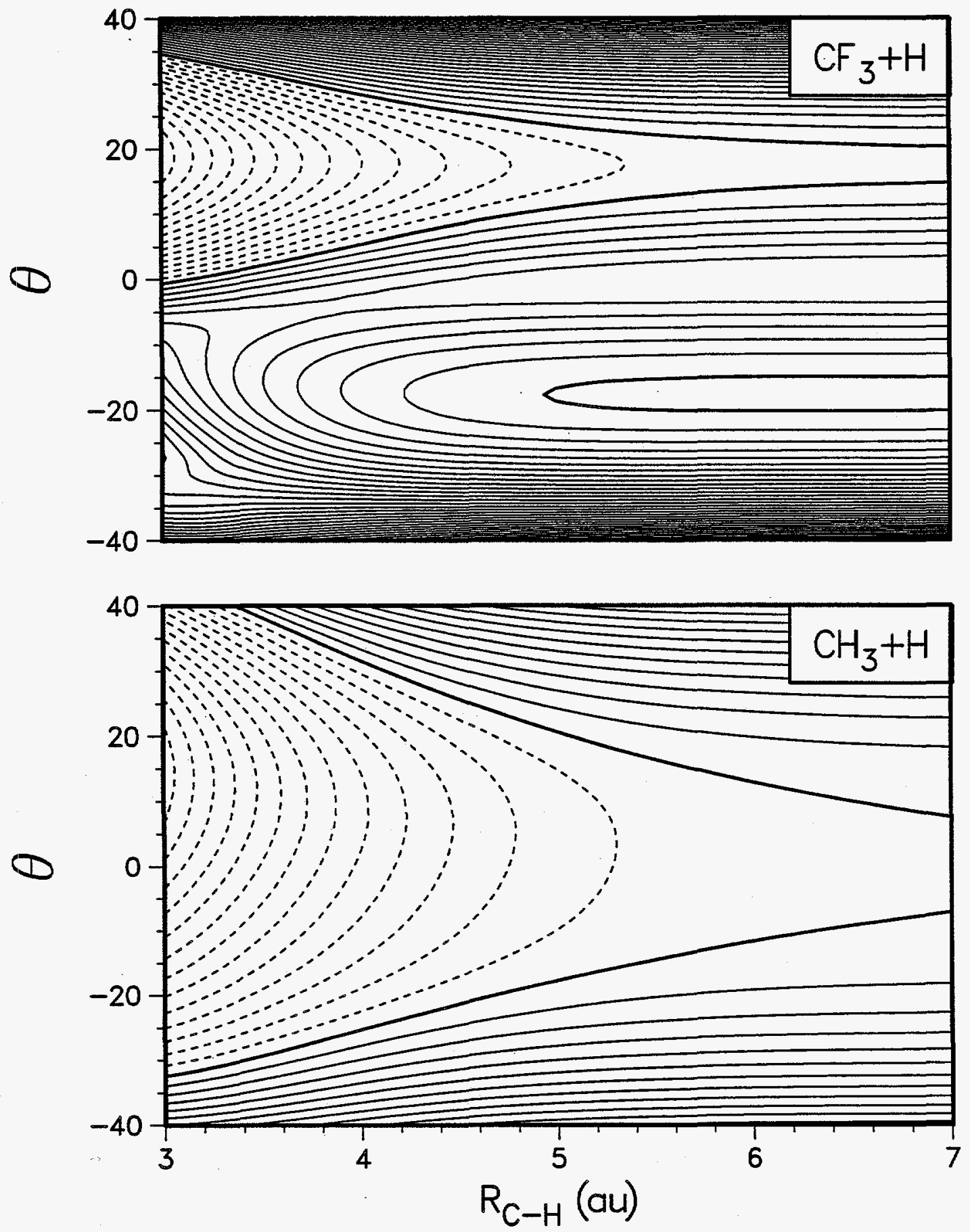


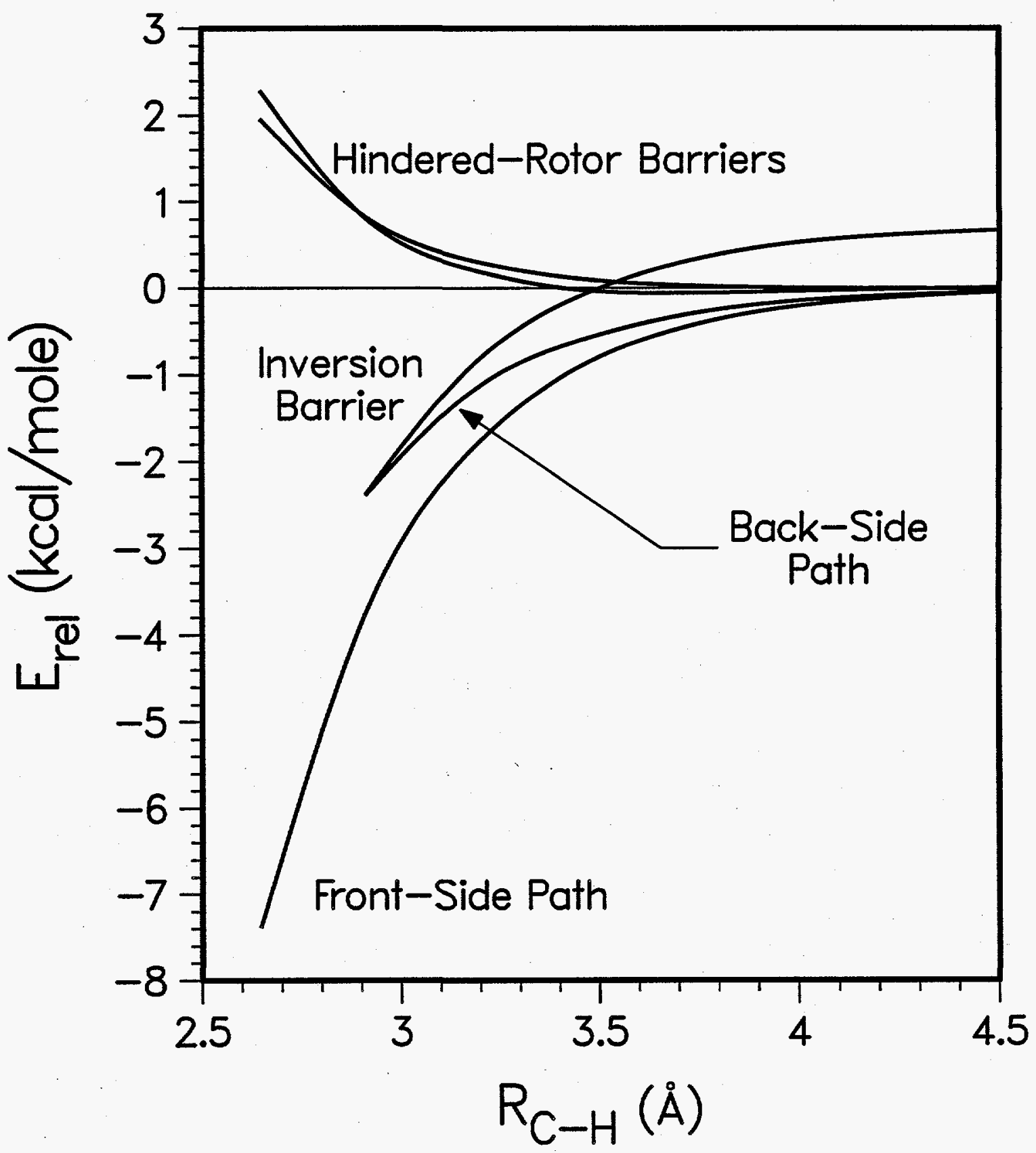




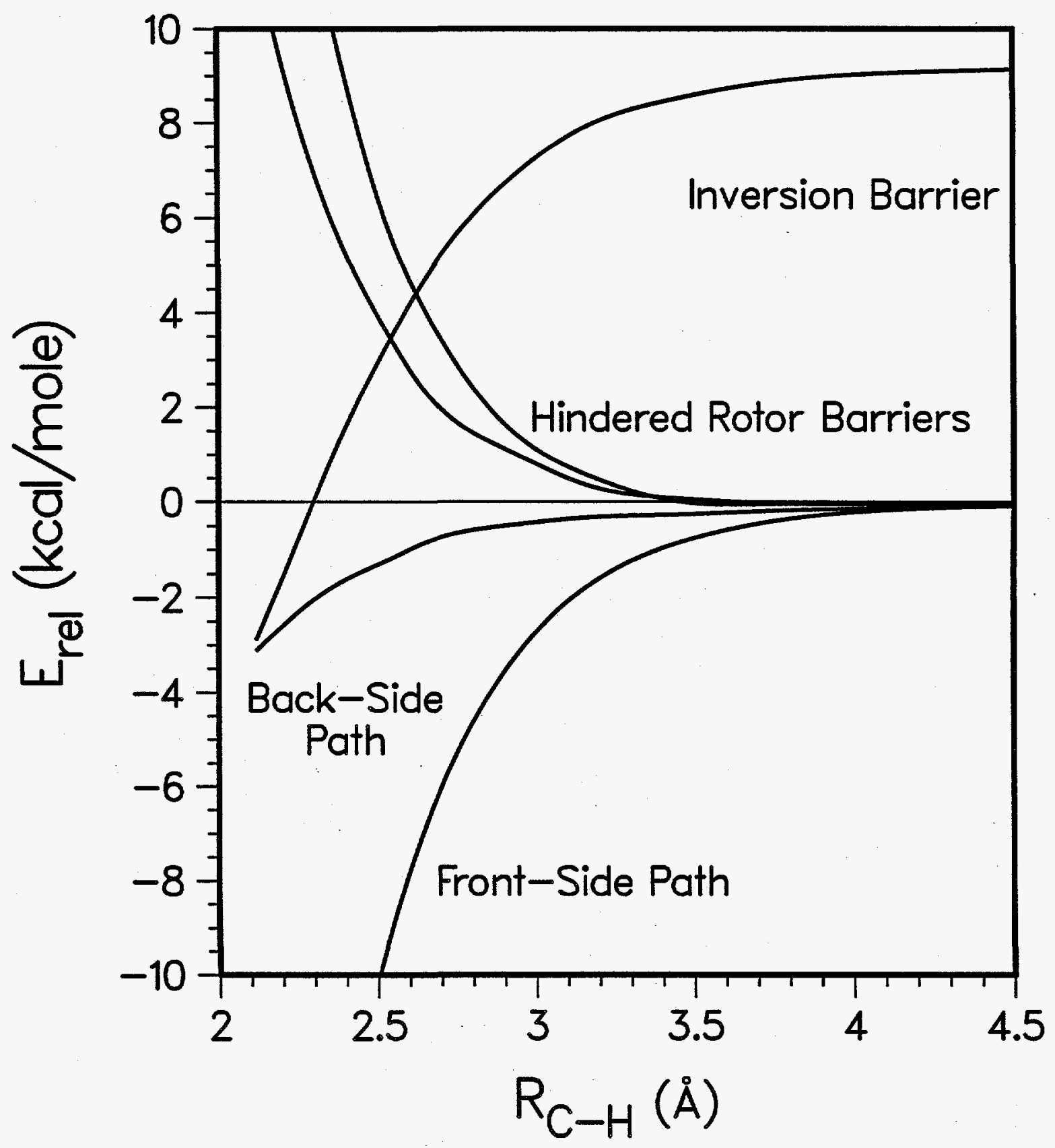

